\title{
14-Year-Old Schoolchildren Can Consent to Get Vaccinated in Tyrol, Austria: What Do They Know about Diseases and Vaccinations?
}

\author{
Peter Kreidl ${ }^{1}$ (D), Maria-Magdalena Breitwieser ${ }^{2}$, Reinhard Würzner ${ }^{1}(\mathbb{D})$ and Wegene Borena ${ }^{3, * \mathbb{C}}$ \\ 1 Department for Hygiene, Microbiology and Public Health, Medical University Innsbruck, \\ 6020 Innsbruck, Austria; peter.kreidl@i-med.ac.at (P.K.); reinhard.wuerzner@i-med.ac.at (R.W.) \\ 2 Department of Internal Emergency Medicine, Klinikum Wels-Grieskirchen, 4600 Wels, Austria; \\ MariaMagdalena.Breitwieser@klinikum-wegr.at \\ 3 Institute of Virology, Department for Hygiene, Microbiology and Public Health, Medical University of \\ Innsbruck, 6020 Innsbruck, Austria \\ * Correspondence: Wegene.borena@i-med.ac.at; Tel.: +43-512-9003-71737
}

Received: 22 September 2020; Accepted: 13 October 2020; Published: 15 October 2020

\begin{abstract}
In Austria, consent to receiving vaccines is regulated at the federal state level and in Tyrol, children aged 14 years are allowed to consent to receiving vaccination. In August 2017, we investigated determinants associated with vaccine hesitancy, having been vaccinated against measles and human papillomavirus (HPV) and the intention to vaccinate among schoolchildren born in 2002 and 2003. Those who consider measles and HPV a severe disease had a significantly higher intention to be vaccinated (prevalence ratio (PR) of 3.5 (95\% CI 1.97-6.32) for measles and a PR of 3.2 (95\% CI 1.62-6.35) for HPV). One-third of the participants (32.4\%; 95\% CI 27.8-37.4) were not aware that they are allowed to consent to receiving vaccines. The most common trusted source reported by respondents $(n=311)$ was the medical doctor $(80.7 \%$; $95 \%$ CI $75.7-84.7)$. The main finding related to the aim of the study was that the proportion of objectors is below $4 \%$ and therefore it should still be possible to reach measles elimination for which a 95\% uptake is necessary. Although the proportion of objectors is not higher compared to adults, we recommend to intensify health education to increase health literacy.
\end{abstract}

Keywords: vaccination; vaccine hesitancy; adolescent; measles; mumps rubella; human papilloma virus; informed consent

\section{Introduction}

In 2019, vaccine hesitancy (VH) was stated as one of the ten key health threats by the World Health Organization (WHO) [1]. The majority of studies investigated $\mathrm{VH}$ among parents and health care providers [2-4], but little is known on the knowledge, perceptions, attitudes and practices of adolescents and young adults who will be future parents. In recent years, in several Western European countries, the highest incidence of several vaccine preventable diseases (VPD) such as measles, mumps or pertussis was reported among adolescents [5]. In Austria, all childhood vaccinations are recommended including influenza and most of them free of charge until age (except vaccination against meningococcal $B$, tick-borne encephalitis, varicella and influenza vaccination) [6].

Health literacy is an important determinant of empowerment and decision-making including decisions about vaccinations. In a survey that assessed the level of health literacy in a population among several European countries, Austria had one of the lowest literacy indexes [7]. In Austria, educational curricula for schoolchildren neither include information on vaccine preventable diseases (VPD) nor on the safety and effectiveness of vaccination and its impact [8]. Youth protection laws are 
the responsibility of each federal state in Austria. Adolescents aged 14 years and above (attending grade 8 and grade 9 school classes) are legally allowed to consent on vaccination on their own in Tyrol [9]. This combination of a poor health literacy index and the freedom to decide on one's own immunization status at a very young age motivated us to investigate several aspects of immunization behavior among this age group.

The main aim of this cross-sectional study was to describe the knowledge, perceptions, vaccination status and intention to vaccinate among the youngest of these adolescents. We aimed to assess the level of $\mathrm{VH}$ and factors responsible for that at this early stage of self-determined life of young individuals. The information obtained from this survey will be a useful tool in tailoring immunization strategies in the region and could also be useful for other regions facing a similar situation.

\section{Materials and Methods}

\subsection{Study Population}

The target populations of this study were children/adolescents aged 14 years attending eighth and ninth grade school classes in Tyrol. In Tyrol, one of Austria's nine states with 745,049 inhabitants [10], the number of students attending those classes in 210 schools was 13,819 in 2017 [9].

\subsection{Study Design and Sampling Strategy}

A sample size of 374 participants was calculated to assess a prevalence with $+/-5 \%$ precision [11]. Taking a population size of 13,819 14-year-olds, we used a sample-proportional-to-size design [12] to select participants and assumed a worst-case scenario of a $50 \%$ prevalence of knowledge factors. Only children born in 2002 or 2003 were included in the study.

The school authorities provided aggregated lists with all 210 classes with schoolchildren in grades 8 and 9 attended by children born in 2002 or 2003. This list of eligible classes including the number of schoolchildren was sorted alphabetically. The cumulative number of schoolchildren and subsequently a sampling interval for 30 clusters were calculated (sampling interval $=461$ ). A random number between one and the sampling interval was chosen (random number $=132$ ) and thirty classes were identified. Each entire class was recruited in which a systematically selected schoolchild was part of. All schoolchildren of a selected class were included resulting in 2443 potential participants. For each school, two substitute school classes were selected in case of non-response.

The headmasters of all 30 selected schools were contacted by telephone and email and were encouraged to support the participation of schoolchildren in the study. A facilitation letter from the regional school authority to enhance participation was attached. Additionally, all school physicians of selected schools were briefed and supported our activities.

\subsection{Questionnaire and Data Collection}

The potential participants were informed by the responsible teachers of each class about the study and received an information letter including the informed consent which they had to bring home to their parents, who were encouraged to sign it. Schoolchildren then brought the signed informed consent back to school. After having obtained informed consent from the parents, data were collected between June 2017 and May 2018 using an anonymized, web-based standardized self-administered questionnaire. Data were entered in a password-protected survey tool, which could be accessed from personal mobile phones or by using computers in dedicated rooms in the schools [6]. Data collection took place during school hours to increase the participation rate.

The survey contained 42 questions about knowledge, attitudes and intention to vaccinate and history of measles mumps rubella (MMR) and human papilloma virus (HPV) vaccine uptake. Personal information contained sex, birth cohort, school type, migratory background and residential district. 
The standardized questionnaire was adapted from available survey tools $[13,14]$ and pilot-tested with pupils of the same age to ensure high comprehensibility. Several questions were coded in 5 point Likert scales such as "not being against vaccinations in general but deciding for each vaccination separately", "vaccinations are mainly the interest of pharmaceutical companies" or "I am not interested in the discussion about vaccinations". For these questions, the inconclusive category (neither agree nor disagree) was excluded to estimate the association with self-reported vaccination and the intention to vaccinate. Partially missing data were excluded from the analysis.

The study was conducted in accordance with the Declaration of Helsinki and the protocol was approved by the Ethics Committee of the Medical University Innsbruck (EK 1072/2017) and the regional school authority.

\subsection{Data Entry and Analysis}

The anonymous data were extracted from the web-based data entry tool and analyzed in Epi.info ${ }^{\mathrm{TM}}$ version 7.2.2.2 (CDC, Atlanta).

We described the distribution/prevalence of the answers for each question excluding missing answers. We compared the prevalence of knowledge between questions using a chi square test and considered a value below 0.05 as statistically significant. We estimated the prevalence ratio and the 95\% confidence interval of potential determinants using the Taylor series in Epi.info ${ }^{\mathrm{TM}}$ between the vaccinated and unvaccinated group using univariate analysis. Exposures were determinants such as sex, migratory background, preference of alternative medicine or VH and outcome was defined as reported MMR or HPV vaccination or intention to vaccinate against MMR or HPV.

\subsection{Definitions}

- Vaccinated: recall of at least one dose of MMR or HPV;

- Unvaccinated: reported not having received at least one dose of MMR or HPV;

- Unknown vaccination status: non-responders, persons who did not recall or did not want to answer the question about previous MMR or HPV vaccinations;

- $\quad$ Migratory background: either born outside Austria or at least one parent born outside Austria.

\section{Results}

\subsection{Characteristics of Study Participants}

The questionnaires were completed in an anonymous way and only the school type was recorded, therefore no response rate by class or school could be calculated.

Of the 518 respondents, 367 participants were born in 2002 or 2003 and thus eligible for inclusion in our study (Figure 1).

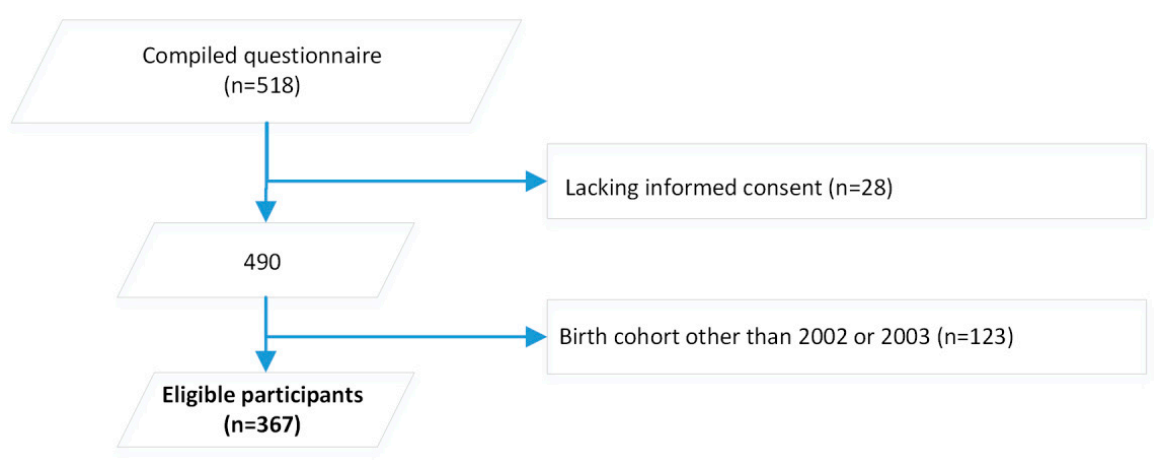

Figure 1. Number of participants after application of exclusion criteria $(n=367)$. 
Of the 367 participants, more than half were born in 2002. Fifty-eight percent of participants were males. Participants were residents from eight of the nine Tyrolean districts. The only district without participants was the smallest Tyrolean district accounting for $4 \%$ of the birth cohorts of interest. On average, $2.2 \%$ of eligible schoolchildren participated in our survey, ranging from $0.2 \%$ to $4.5 \%$ by district. Participants from the four districts with the highest number of eligible schoolchildren accounted for $91.7 \%$. These districts were also the ones with the highest number of schools per inhabitant. The majority of participants were born in Austria, and $1 / 3$ reported a migratory background (Table 1).

Table 1. Demographic characteristics of survey participants $(n=367)$.

\begin{tabular}{|c|c|c|c|c|}
\hline Category & Sub-Category & $\begin{array}{l}\text { Number of } \\
\text { Participants }\end{array}$ & $\begin{array}{c}\text { Proportion of } \\
\text { Participants (\%) }\end{array}$ & $\begin{array}{l}95 \% \text { Confidence } \\
\text { Interval }\end{array}$ \\
\hline \multicolumn{5}{|c|}{ Sex } \\
\hline & Males & 212 & 57.8 & $52.7-62.7$ \\
\hline & Females & 150 & 40.1 & $36.0-46.0$ \\
\hline & unknown & 5 & 1.4 & $0.6-3.2$ \\
\hline \multicolumn{5}{|c|}{ Birth cohort } \\
\hline & 2002 & 210 & 57.2 & $52.1-62.2$ \\
\hline & 2003 & 157 & 42.8 & $37.8-47.9$ \\
\hline \multicolumn{5}{|l|}{ Total population } \\
\hline $\begin{array}{c}2002 / 2003 \text { by } \\
\text { district }\end{array}$ & 13,819 & & $\%$ of total & \\
\hline 3167 & Innsbruck Land & 143 & 39.0 & $34.1-44.0$ \\
\hline 2093 & Innsbruck Stadt & 66 & 18.0 & $14.4-22.2$ \\
\hline 2060 & Kufstein & 45 & 12.3 & $9.3-16.0$ \\
\hline 1609 & Schwaz & 79 & 21.5 & $17.6-26.0$ \\
\hline 1182 & Imst & 18 & 4.9 & $3.1-7.6$ \\
\hline 1181 & Kitzbühel & 3 & 0.8 & $0.3-2.4$ \\
\hline 1004 & Lienz & 2 & 0.5 & $0.2-2.0$ \\
\hline 958 & Landeck & 7 & 1.9 & $0.9-3.9$ \\
\hline 565 & Reutte* & 0 & - & - \\
\hline & unknown & 4 & 1.1 & $0.4-2.8$ \\
\hline \multicolumn{5}{|c|}{ Place of birth } \\
\hline & Austria & 339 & 92.4 & $89.2-94.7$ \\
\hline & Outside Austria & 20 & 5.5 & $3.6-8.3$ \\
\hline & unknown & 8 & 2.2 & $1.1-4.2$ \\
\hline \multicolumn{5}{|c|}{ Migratory background } \\
\hline & $\begin{array}{l}\text { Both parents born } \\
\text { in Austria }\end{array}$ & 241 & 65.7 & $60.7-70.3$ \\
\hline & $\begin{array}{l}\text { One parent born } \\
\text { outside Austria }\end{array}$ & 57 & 15.5 & $12.2-19.6$ \\
\hline & $\begin{array}{l}\text { Both parents born } \\
\text { outside Austria }\end{array}$ & 56 & 15.3 & 11.9-19.3 \\
\hline & unknown & 13 & 3.5 & $2.1-6.0$ \\
\hline
\end{tabular}

\subsection{General Knowledge on Vaccinations}

The majority of participants knew about the success of vaccinations to reduce the burden and mortality of communicable diseases (82.6\%; 95\% CI 78.2-86.2). Two-thirds disagreed with the statement that the risks of vaccination outweigh the benefits $(65.4 \% ; 95 \%$ CI 60.2-70.3). The mechanism of live vaccines was known by more participants (45.8\%; 95\% CI 40.6-51.1) compared to the mechanism of inactivated vaccines (21.7\%; 95\% CI 17.7-26.3) $(p<0.0001)$. The fact that smallpox has been eradicated was known by one-third of participants (31.1\%; 95\% CI 26.4-36.2). Only one-third (34.9\%; 
95\% CI 30.0-40.1) of participants were aware that they did not need their parents' consent to get vaccinated when aged 14 years and older.

\subsection{Knowledge about Measles Disease and Vaccination}

Most participants (79.4\%; 95\% CI 74.7-83.3) knew about the high transmissibility of measles and that measles can infect anybody who is not immune irrespective of age (68.0\%; 95\% CI 62.8-72.4). Nearly half of the participants (45.1\%; 95\% CI 39.9-50.5) agreed with the statement that measles can be acquired several times during life and does not provide life-long immunity. More than half of the participants were aware that measles cases and outbreaks frequently occur in Austria (56.6\%; 95\% CI 51.2-61.7) and 35.5\% (95\% CI 30.7-40.6) knew that MCV is a live attenuated vaccine. Less than a third of participants $(28.8 \%$; $95 \%$ CI $24.3-33.8)$ knew that the vaccine effectiveness of measles vaccination is above $80 \%$.

\subsection{Knowledge about HPV Disease and Vaccination}

More than half of the participants (55.1\%; 95\% CI 49.7-60.3) disagreed that HPV is a childhood disease and knew that it is mainly transmitted via sexual contact $(62.4 \%$; 95\% CI 57.1-67.4). Cervical cancer caused by HPV was known by twice as many participants (40.8\%; 95\% CI 35.8-46.0) compared to oropharyngeal cancer $(18.4 \%$; 95\% CI 14.7-22.8) $(p<0.0001)$ and more than a quarter knew that HPV infection can either cause genital warts $(28.0 \%$; 95\% CI 23.6-33.0) or present as a subclinical infection (26.9\%; 95\% CI 22.6-31.8). Around two-thirds of the participants knew (67.2\%; 95\% CI 62.0-72.0) that HPV vaccination is recommended for both sexes, and provided in schools, free of charge, for children between 9 and 12 years of age (27.6\%; 95\% CI 23.1-32.6). One in five participants knew $(22.1 \%$; $95 \%$ CI $18.0-26.8)$ that the vaccine effectiveness of HPV vaccine is above $80 \%$.

\subsection{Perception of the Severity of Diseases}

Poliomyelitis was perceived most frequently as severe or rather severe VPD followed by HPV, tetanus, tick-borne encephalitis (TBE), diphtheria and mumps. Measles ranked at position seven prior to rubella and pertussis. Influenza was considered by less than a third of the participants as a severe or rather severe disease (Table 2).

Table 2. Perception of the severity of different vaccine-preventable diseases by study participants.

\begin{tabular}{ccc}
\hline Disease & Severe or Rather Severe & $\mathbf{9 5 \%}$ CI \\
\hline Polio & $94.9 \%$ & $91.8-97.1$ \\
HPV & $87.8 \%$ & $83.2-91.5$ \\
Tetanus & $87.8 \%$ & $83.2-91.6$ \\
TBE & $86.9 \%$ & $82.6-90.5$ \\
Diphtheria & $71.4 \%$ & $64.5-77.3$ \\
Mumps & $68.2 \%$ & $62.1-73.9$ \\
Measles & $67.6 \%$ & $61.9-72.9$ \\
Rubella & $55.2 \%$ & $49.1-61.3$ \\
Pertussis & $52.7 \%$ & $46.7-58.7$ \\
Influenza & $32.2 \%$ & $27.2-37.7$ \\
\hline
\end{tabular}

\subsection{Intention to Vaccinate}

The intention to vaccinate was highest for TBE and lowest for influenza and similar, but not identical to the perception of the severity of diseases. The highest association between the perception of severity and intention to vaccinate was for TBE followed by measles and HPV (Table 3). 
Table 3. Association (prevalence ratio (PR) and 95\% confidence interval (95\% CI)) between the perception of the severity of disease and intention to vaccinate against the disease.

\begin{tabular}{ccc}
\hline Disease & PR & 95\% CI \\
\hline TBE & 7.7 & $3.81-15.57$ \\
Measles & 3.5 & $1.97-6.32$ \\
HPV & 3.2 & $1.62-6.35$ \\
Diphtheria & 3.1 & $1.62-6.00$ \\
Mumps & 3.0 & $1.74-5.18$ \\
Pertussis & 2.5 & $1.67-3.73$ \\
Rubella & 2.3 & $1.42-3.84$ \\
Tetanus & 2.1 & $0.85-5.02$ \\
Poliomyelitis & 1.8 & $0.50-6.31$ \\
Influenza & 1.4 & $1.08-1.83$ \\
\hline
\end{tabular}

\subsection{Vaccine Hesitancy}

Less than four percent $(3.6 \%, n=12 ; 95 \%$ CI 2.1-6.2) of respondents fully agreed with the statement that "vaccinations are unnecessary and harmful" and were therefore classified as objectors, whilst 19.8\% (95\% CI 15.9-24.4) were classified as hesitant (partly agreed, or neither agreed nor disagreed) and $76.6 \%(95 \%$ CI 71.7-80.8) as pro-vaccination.

Nearly half of the participants $(42.6 \%$; $95 \%$ CI $37.4-48.1)$ completely or partly disagreed with the statement that "vaccinations are mainly of interests of pharmaceutical companies", $21.0 \%$ (95\% CI 17.0-25.7) agreed and 36.3\% (95\% CI 31.4-41.6) neither agreed nor disagreed.

The majority of participants completely or partly agreed $(74.5 \%$; $95 \%$ CI $69.5-78.7)$ with the statement that they are not against vaccinations in general but would make a "selective decision for each vaccination", $16.5 \%$ (95\% CI 12.9-20.9) completely or partly disagreed and 9.0\% (95\% CI 6.4-12.6) were undecided.

More than two-thirds $(69.7 \%$; $95 \%$ CI $64.5-74.4)$ of the participants completely or partly agreed in having "interest in the discussion about vaccination", 15.9\% (95\% CI 12.4-20.2) completely or partly disagreed and $14.4 \%$ (95\% CI 11.1-18.6) were undecided (Figure 2).

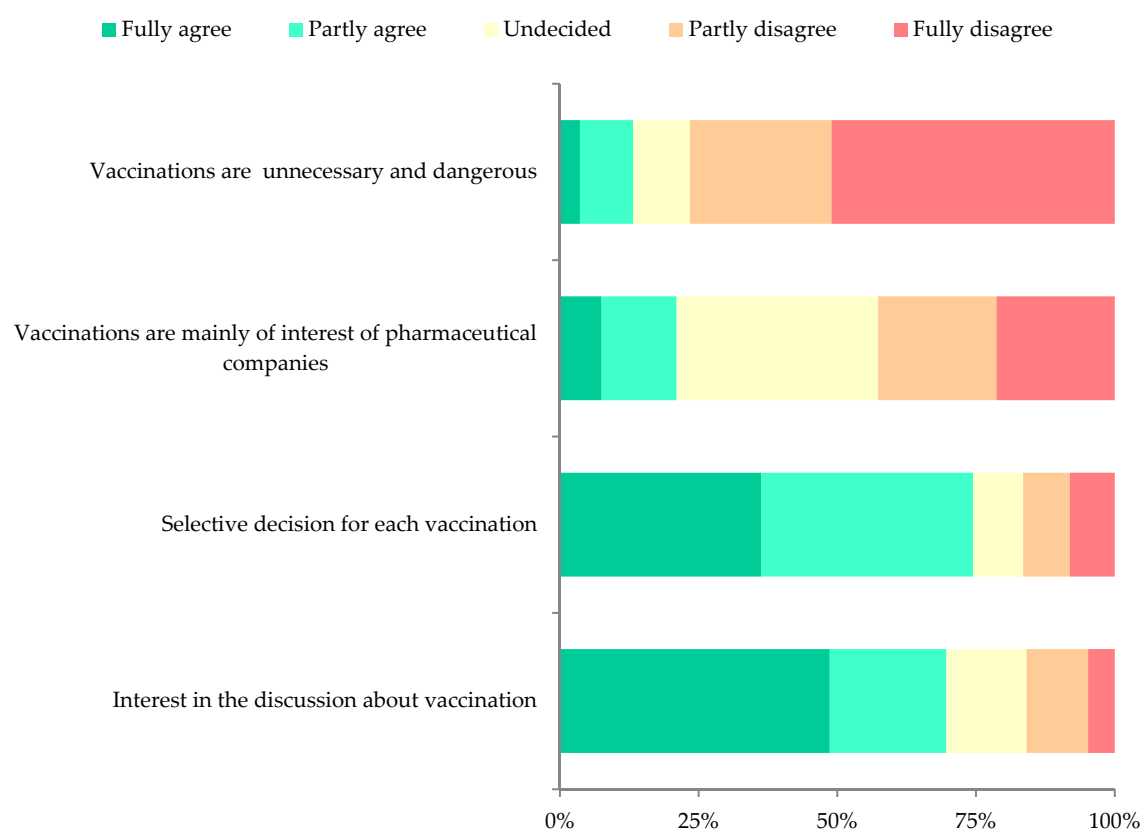

Figure 2. Distribution of vaccine hesitancy determinants. 
Among the twelve respondents classified as objectors, three of seven who provided information reported having been vaccinated against measles, but none against HPV.

\subsection{Reported MMR and HPV Vaccination Status}

More than half of the 367 participants, 51.8 (95\% CI 46.7-56.8), did not want to respond or did not recall their vaccination status related to measles and even more related to HPV (65.4\%; 95\% CI 60.4-70.1). Among respondents, the estimated proportion having been vaccinated against measles was $83.1 \%$ (95\% CI 76.7-88.3) and 38.6\% (95\% CI 30.1-47.6) against HPV. The vast majority of participants did not recall the number of doses received against measles (83.7\%; 95\% CI 79.5-87.1) or HPV (91.0\%; 95\% CI 87.6-93.5). More girls compared to boys recalled the number of received doses of either vaccine (PR 1.28; 95\% CI 1.13-1.44).

The proportion of females who recalled having been vaccinated against measles was slightly higher compared to males $(87.6 \%)$ versus $(79.3 \%)(\mathrm{PR}=1.3: 95 \% \mathrm{CI} 0.95-1.84)$ and so was the recalled HPV uptake (31.6\% of males and $44.1 \%$ of females vaccinated) (PR $1.4 ; 95 \%$ CI 0.89-2.07).

\subsection{Determinants of Vaccine Hesitancy}

\subsubsection{Demographic Factors}

The PR for females being pro-vaccination was 1.2 (95\% CI 0.95-1.44) and for not having a migratory background, it was 1.3 (95\% CI 0.91-1.88), therefore neither sex nor migratory background were associated with hesitancy.

\subsubsection{Perception of the Severity of Diseases}

The association (PR) between the perception of the severity of disease and having been classified as pro-vaccination was significant for polio, HPV, tetanus and diphtheria (Table 4).

Table 4. Association (prevalence ration (PR) and 95\% confidence interval (95\% CI)) between the perception of the severity of disease and having been classified as pro-vaccine.

\begin{tabular}{ccc}
\hline Disease & PR & $\mathbf{9 5 \% ~ C I ~}$ \\
\hline Poliomyelitis & 2.3 & $1.14-4.77$ \\
HPV & 2.3 & $1.34-3.86$ \\
Tetanus & 2.3 & $1.34-3.86$ \\
Diphtheria & 2.2 & $1.29-3.76$ \\
TBE & 1.4 & $0.77-2.64$ \\
Influenza & 1.4 & $0.80-2.54$ \\
Measles & 1.3 & $0.82-2.16$ \\
Mumps & 1.1 & $0.64-1.98$ \\
Rubella & 1.1 & $0.67-1.76$ \\
Pertussis & 0.9 & $0.54-1.50$ \\
\hline
\end{tabular}

The PR between the perception of the severity of measles and recalled measles vaccination was 1.8 (0.93-3.42) and thus higher compared to the association of the intention to vaccinate. This was the opposite for HPV (PR = 1.7; 95\% CI 0.83-1.65).

3.9.3. Having Been Vaccinated against Measles and HPV and the Intention to Vaccinate

Classified as hesitant (objectors excluded) was associated, with a PR of 3.7 (95\% CI 1.91-7.23), with not being vaccinated against measles, and a PR of 1.6 (95\% CI 1.18-2.01) with not having been vaccinated against HPV, compared to the pro-vaccination group.

The PR of hesitant persons not intending to vaccinate against tetanus was the highest, followed by TBE and HPV. Measles was ranked at position seven (Table 5). 
Table 5. Association (prevalence ratio (PR) and 95\% confidence interval (95\% CI) ) between having been classified as hesitant and intention to vaccinate.

\begin{tabular}{ccc}
\hline Disease & PR & $\mathbf{9 5 \%}$ CI \\
\hline Tetanus & 5.6 & $2.67-11.55$ \\
TBE & 5.2 & $2.23-12.03$ \\
HPV & 5.1 & $2.67-9.87$ \\
Diphtheria & 3.9 & $2.16-7.07$ \\
Mumps & 3.6 & $2.17-6.08$ \\
Measles & 3.4 & $1.86-6.14$ \\
Pertussis & 2.4 & $1.72-3.30$ \\
Rubella & 2.3 & $1.44-3.74$ \\
Poliomyelitis & 2.1 & $1.02-4.39$ \\
Influenza & 1.4 & $1.15-1.70$ \\
\hline
\end{tabular}

\subsubsection{Other Factors}

Agreement with the statement to take a selective decision for each vaccination was similar between the hesitant and the pro-vaccination group ( $\mathrm{PR}=1.1 ; 95 \% \mathrm{CI}$ 0.63.3.52). No interest in discussions about vaccination was strongly associated with hesitancy ( $P R=5.5 ; 95 \%$ CI 3.41-9.00) as well as agreeing with the statement that vaccinations are mainly the interest of pharmaceutical companies ( $\mathrm{PR}=2.9$; 95\% CI 2.06-4.15).

\subsection{Other Determinants of Having Been Vaccinated against Measles and HPV}

More than one-third of participants (41.3\% 95\% CI 34.8-48.1) stated that they trust alternative medicine such as homeopathy, acupuncture or Ayurveda more compared to traditional medicine. More trust in alternative medicine was associated with not having been vaccinated against measles (PR 1.6, 95\% CI 1.07 to 2.51) and HPV (PR 2.0, 95\% CI 1.05 to 3.71). The results were similar when stratifying for migratory background and sex.

The majority of participants reported to possess a vaccination card (97.4\%; 95\% CI 95.0-98.7). The reported possession of a vaccination card was strongly associated with having been vaccinated against measles (PR 22.5, 95\% CI 2.61-193.07) and not calculable for HPV, as all HPV-vaccinated participants reported to possess a vaccination card.

\subsection{Determinants of the Intention to Vaccinate}

Preference of alternative medicine was associated with not intending to vaccinate against measles and mumps (Table 6). No other determinants such as sex or migratory background were significantly associated with the intention to vaccinate against any of the investigated diseases.

Table 6. Association (prevalence ratio (RR) and 95\% confidence interval (95\% CI)) of the preference of alternative medicine and intention to vaccinate.

\begin{tabular}{ccc}
\hline Disease & PR & 95\% CI \\
\hline Mumps & 2.4 & $1.29-4.54$ \\
TBE & 2.4 & $0.88-6.39$ \\
Measles & 2.3 & $1.13-4.77$ \\
HPV & 1.9 & $0.84-4.23$ \\
Pertussis & 1.4 & $0.88-2.21$ \\
Rubella & 1.4 & $0.82-2.42$ \\
Poliomyelitis & 1.4 & $0.72-2.89$ \\
Tetanus & 1.3 & $0.52-3.19$ \\
Diphtheria & 1.2 & $0.52-2.59$ \\
Influenza & 1.1 & $0.82-1.35$ \\
\hline
\end{tabular}




\subsection{Information Sources Related to Vaccinations}

Sixty-three (19.3\%; 95\% CI 15.4-23.9) of 327 participants who responded reported that they actively searched for information related to vaccination. Medical doctors and the family were by far the most common sources of information (Table 7).

Table 7. Most common trusted sources of information $(n=311)$.

\begin{tabular}{ccc}
\hline Source of Information & Proportion & 95\% CI \\
\hline Medical doctor & $80.7 \%$ & $76.0-84.7$ \\
Family & $7.1 \%$ & $4.7-10.5$ \\
Public health authority including ministry of health & $5.5 \%$ & $3.4-8.6$ \\
Pharmacy & $3.5 \%$ & $2.0-6.2$ \\
Internet and social media & $1.9 \%$ & $0.9-4.1$ \\
Friends & $1.0 \%$ & $0.3-2.8$ \\
General media (newspaper and TV) & $0.3 \%$ & $0.1-1.8$ \\
\hline
\end{tabular}

\section{Discussion}

The unique aspect of this study was that we targeted young adolescents, namely 14 year olds. The significance lies in that this young population has the right to decide on their vaccination status in Austria. The main finding related to the aim of the study was that the proportion of objectors is below $4 \%$ and therefore it should still be possible to reach measles elimination for which a $95 \%$ vaccine uptake is necessary. The proportion of hesitant persons was less than $20 \%$ and strongly associated with not having been vaccinated against measles and HPV as well as the intention to vaccinate compared to the pro-vaccination group.

More than half of the participants did not recall their self-reported MMR vaccination status. The reported MMR coverage was $83 \%$ and similar to the reported coverage [15]. The HPV reported coverage was $40 \%$ and much lower compared to measles despite the fact that our study population was a target group for the free of charge school program. Girls recalled their vaccination status more frequently than boys.

Considering a disease as severe was associated with a positive intention to vaccinate as well as possessing a vaccination card; preference of alternative medicine was negatively associated. These determinants were described previously as being associated with non-vaccination among adults [14,16-20]. Therefore, it is important to integrate disease-specific information in school curricula.

Measles was perceived as the seventh most severe vaccine-preventable disease in our survey in contrast to TBE, which was considered as the second most severe disease by our participants. This lower perception of severity may have been partly due to the very active TBE vaccine promotion in all media and on billboards with ticks attacking humans in Austria. The estimated TBE vaccine coverage in Austria in 2018 was 85\% [21] and thus higher compared to the coverage of measles. Without any doubt, TBE is a severe disease and since 2016, an increase in case numbers with 154 hospital-admitted patients in 2018 was reported in Austria. Fifty-two percent of them were classified as severe including five deaths [22]. Due to the high TBE vaccine uptake, the incidence of TBE declined in Austria from 4.9 cases per 100,000 inhabitants prior to the implementation of vaccination in 1981 to 1.9 per 100,000 inhabitants in 2018 [22,23].

The distribution of vaccine hesitancy $(\mathrm{VH})$ was similar compared to a recently published national study of VH among parents of children aged 16 to 36 months in Italy [3]. Nevertheless, compared to the Italian study, we observed a higher proportion of objectors and hesitant participants but much lower compared to a study conducted in 2014 among 350 Austrian patients in an emergency department [24].

It was surprising that only one-third of participants knew about their right to decide to get vaccinated at age 14 [9] and that these minors could chose to be vaccinated over parental objections. This lack of awareness that schoolchildren do not need their parents' consent to vaccinate was neither 
associated with vaccine hesitancy nor the intention to vaccinate against measles or HPV, but this may change if more schoolchildren are aware about their rights in the future.

In Austria, the second lowest level of health literacy among eight European countries was described in 2015 , where more than half $(56.4 \%)$ of the population was classified as having inadequate or problematic health literacy [7]. Without comparison to other countries or regions, it remains difficult to compare this specific aspect of health literacy. The right to decide at this young and the low health literacy are a detrimental combination which urgently needs attention from health policy makers.

Calculation was defined by Betsch et al. as "individuals' engagement in extensive information searching" [25] and can lead to non-vaccination. In our study, interest in discussion about vaccinations was positively associated with both the intention to vaccinate and reported vaccination against measles and HPV.

Trust in health care providers is a key determinant for vaccine uptake [26]. Only few participants reported having actively searched for information related to vaccination. Medical doctors were by far the most important and most trustworthy source, which is similar to published results for adults [27]. Smith et al. suggested that the effect of information sources on vaccine uptake needs further studies [28]. The responsibility of health professionals is vital with respect to actively recommending vaccination.

One important limitation of our study was that the decision of schools to participate was mainly dependent on the headmaster's agreement which may have resulted in selection bias. However, the very active role of school physicians in convincing headmasters and recruiting participants positively influenced the willingness of headmasters to participate in our survey.

Another important limitation of our study was that many participants did not respond to all questions. This limited the power of the study and thus could have masked other significant associations. Furthermore, we could not conduct a sensitivity analysis to investigate potential correlation structures within each class, as data on classes were not obtained. Generalizability is another limitation of our study as the study area represented only one region of Austria, however, the sample size was still sufficient to draw plausible conclusions.

We defined the vaccination status by history only and did not check the vaccination records due to logistical reasons. This may also have biased our results.

Following measles outbreaks in the United States in 2019, some affected children pursued vaccination against the parents' resistance to vaccination such as Ethan Lindenberger [29]. He was only able to get vaccinated at the age of 18 years. In Tyrol, Austria, children could already decide at age 14 to get vaccinated without parental permission [9]. The insufficient coverage of many vaccines and repeated outbreaks triggered our survey to assess vaccine hesitancy among adolescents. The Society for Adolescent Health and Medicine suggests in a position paper that minor consent should be granted. Only one-third of participants were aware that they are allowed to consent to vaccination without parental permission. This fact and the lack of knowledge about the safety and effectiveness of nearly every fifth 14-year-old participant demonstrate that awareness raising in this age group could be an important instrument to increase coverage, as well as the low level of health literacy.

Already two years prior to our study, we implemented school lectures targeting VPD and their respective vaccinations as we consider it very important that every child should be confronted at least once during her/his "school-life" with relevant communicable diseases and the safety and effectiveness of vaccinations, which are considered the most effective preventive measures besides safe drinking water and hygiene. We continue these activities now for several years and provided baseline lectures in easy to understand language to the Ministry of Education which can be used by any school doctor or biology teacher. Furthermore, transparent, easy to understand and pro-vaccination messages should be distributed by social media.

Furthermore, we use the European immunization week each year to raise awareness among the general population, where we work closely together with the Austrian Medical Student Association and other important stakeholders. 


\section{Conclusions}

We conclude that the level of knowledge about vaccine-preventable diseases is limited in our region. We recommend a different strategy to approach adolescents and increase their knowledge about vaccine-preventable diseases.

Author Contributions: P.K. contributed to the conceptualization, methodology, validation, investigation, data curation, formal analysis, original draft preparation, supervision and project administration. M.-M.B. contributed to the data curation, software, methodology, investigation and review, R.W. and W.B. contributed to the review, editing and resources. All authors have read and agreed to the published version of the manuscript.

Funding: This research received no external funding.

Acknowledgments: The authors want to thank all school physicians, especially Christina Schwarz and Petra Rainer, teachers, headmasters for their administrative and technical support and all schoolchildren for participation in the study.

Conflicts of Interest: The authors declare no conflict of interest.

\section{References}

1. WHO. Ten threats to global health in 2019. Available online: https://www.who.int/news-room/spotlight/tenthreats-to-global-health-in-2019 (accessed on 24 July 2019).

2. Dini, G.; Toletone, A.; Sticchi, L.; Orsi, A.; Bragazzi, N.L.; Durando, P. Influenza vaccination in healthcare workers: A comprehensive critical appraisal of the literature. Hum. Vaccin. Immunother. 2018, 14, 772-789. [CrossRef] [PubMed]

3. Giambi, C.; Fabiani, M.; D'Ancona, F.; Ferrara, L.; Fiacchini, D.; Gallo, T.; Martinelli, D.; Pascucci, M.G.; Prato, R.; Prato, A.; et al. Parental vaccine hesitancy in Italy-Results from a national survey. Vaccine 2018, 36, 779-787. [CrossRef] [PubMed]

4. Paterson, P.; Meurice, F.; Stanberry, L.R.; Glismann, S.; Rosenthal, S.L.; Larson, H.J. Vaccine hesitancy and healthcare providers. Vaccine 2016, 34, 6700-6706. [CrossRef] [PubMed]

5. ECDC. Who Is at Risk for Measles in the EU/EEA? 2019. Available online: https://ecdc.europa.eu/sites/portal/ files/documents/RRA-Measles-EU-EEA-May-2019.pdf (accessed on 8 August 2019).

6. SurveyMonkey. Available online: https:/www.surveymonkey.co.uk/welcome/sem/?program=7013A000000mwe BQAQ\&utm_bu=CR\&utm_campaign=71700000059184846\&utm_adgroup=58700005410221930\&utm_ content $=43700049188946189 \& u t m \_$medium $=$cpc\&utm_source=adwords\&utm_term=p49188946189\& utm_kxconfid=s4bvpi0ju\&gclid=CjwKCAiA1rPyBRAREiwA1UIy8NiCRhRhRYHcvArfJbtM8_ ai9ORcuLXGP5bVqCYi3EoKdwzzw_cI1xoC-J4QAvD_BwE (accessed on 19 February 2019).

7. Sorensen, K.; Pelikan, J.M.; Rothlin, F.; Ganahl, K.; Slonska, Z.; Doyle, G.; Fullam, J.; Kondilis, B.; Agrafiotis, D.; Uiters, E.; et al. Health literacy in Europe: Comparative results of the European health literacy survey (HLS-EU). Eur. J. Public Health 2015, 25, 1053-1058. [CrossRef] [PubMed]

8. Bundesministerium für Bildung WuF. Grundsatzerlass Gesundheitserziehung 1976. Available online: https: //www.bmbwf.gv.at/Themen/schule/schulrecht/rs/1997-2017/1997_07.html (accessed on 7 January 2019).

9. Rechte und Pflichten als Jugendlicher. Available online: https://www.kija-tirol.at/infos-und-broschueren/ rechtliche-infos-fuer-kinder-und-jugendliche/deine-rechte-und-pflichten (accessed on 19 April 2017).

10. Tirol, L. Bevölkerung. 2016. Available online: http://www.statistik-austria.at/web_de/statistiken/menschen_ und_gesellschaft/bevoelkerung/index.html (accessed on 8 February 2019).

11. Services S-S. Population proportion- Sample Size. 2017. Available online: https://select-statistics.co.uk/ calculators/sample-size-calculator-population-proportion/ (accessed on 14 April 2019).

12. Kirkwood, B.R.; Sterne, J.A.C. Essentials of Medical Statistics, 1st ed.; Wiley-Blackwell: Hoboken, NJ, USA, 1988.

13. Larson, H.J.; Schulz, W.S.; Tucker, J.D.; Smith, D.M. Measuring vaccine confidence: Introducing a global vaccine confidence index. PLoS Curr. 2015, 7. [CrossRef] [PubMed]

14. Sage. Vaccine Hesitancy Survey Questions Related to SAGE Vaccine Hesitancy Matrix. Available online: https://www.who.int/immunization/programmes_systems/Survey_Questions_Hesitancy.pdf (accessed on 16 January 2020). 
15. BMASGK. Impfplan. 2019. Available online: https://www.paediatrie.at/phocadownloadpap/impfplan_ oesterreich_2019.pdf (accessed on 24 January 2019).

16. Chamberlain, A.T.; Seib, K.; Ault, K.A.; Orenstein, W.A.; Frew, P.M.; Malik, F.; Cortés, M.; Cota, P.; Whitney, E.A.S.; Flowers, L.C.; et al. Factors Associated with Intention to Receive Influenza and Tetanus, Diphtheria, and Acellular Pertussis (Tdap) Vaccines during Pregnancy: A Focus on Vaccine Hesitancy and Perceptions of Disease Severity and Vaccine Safety. PLoS Curr. 2015, 7. [CrossRef] [PubMed]

17. Di Pietro, M.L.; Poscia, A.; Teleman, A.A.; Maged, D.; Ricciardi, W. Vaccine hesitancy: Parental, professional and public responsibility. Ann. Ist. Super. Sanià 2017, 53, 157-162. [CrossRef]

18. Larson, H.J.; Jarrett, C.; Schulz, W.S.; Chaudhuri, M.; Zhou, Y.; Dube, E.; Schuster, M.; MacDonald, N.E.; Wilson, R.; SAGE Working Group on Vaccine Hesitancy. Measuring vaccine hesitancy: The development of a survey tool. Vaccine 2015, 33, 4165-4175. [CrossRef] [PubMed]

19. Schmid, P.; Rauber, D.; Betsch, C.; Lidolt, G.; Denker, M.-L. Barriers of Influenza Vaccination Intention and Behavior-A Systematic Review of Influenza Vaccine Hesitancy, 2005-2016. PLoS ONE 2017, 12, e0170550. [CrossRef] [PubMed]

20. Sun, X.; Huang, Z.; Wagner, A.L.; Prosser, L.A.; Xu, E.; Ren, J.; Wang, B.; Yan, W.; Brian, J. Zikmund-Fisher. The role of severity perceptions and beliefs in natural infections in Shanghai parents' vaccine decision-making: A qualitative study. BMC Public Health 2018, 18, 813. [CrossRef] [PubMed]

21. BMASGK. Frühsommer-Meningoenzephalitis (FSME). 2020. Available online: https://www.sozialministerium. at/Themen/Gesundheit/Uebertragbare-Krankheiten/Infektionskrankheiten-A-Z/Fr\%C3\%BChsommerMeningoenzephalitis-(FSME).html (accessed on 8 May 2019).

22. Santonja, I.H.H.; Stiasny, K. Rückblick auf die FSME-Situation 2018, geprägt von sehr hoher Virusaktivität 2019. Available online: https://www.virologie.meduniwien.ac.at/fileadmin/virologie/files/Epidemiologie/ 2019/0219.pdf (accessed on 9 January 2020).

23. ECDC. Tick-borne encephalitis Annual Epidemiological Report for 2018. 2019. Available online: https://www. ecdc.europa.eu/sites/default/files/documents/TBE-annual-epidemiological-report-2018.pdf (accessed on 9 January 2020).

24. Sandhofer, M.J.; Robak, O.; Frank, H.; Kulnig, J. Vaccine hesitancy in Austria: A cross-sectional survey. Wien. Klin. Wochenschr. 2017, 129, 59-64. [CrossRef] [PubMed]

25. Betsch, C.; Schmid, P.; Heinemeier, D.; Korn, L.; Holtmann, C.; Bohm, R. Beyond confidence: Development of a measure assessing the 5C psychological antecedents of vaccination. PLoS ONE 2018, 13, e0208601. [CrossRef] [PubMed]

26. Brown, K.F.; Kroll, J.S.; Hudson, M.J.; Ramsay, M.; Green, J.; Long, S.J.; Vincent, C.A.; Fraser, G.; Sevdalis, K. Factors underlying parental decisions about combination childhood vaccinations including MMR: A systematic review. Vaccine 2010, 28, 4235-4248. [CrossRef] [PubMed]

27. Simone, B.; Carrillo-Santisteve, P.; Lopalco, P.L. Healthcare workers role in keeping MMR vaccination uptake high in Europe: A review of evidence. Euro Surveill. 2012, 17. [CrossRef]

28. Smith, L.E.; Amlôt, R.; Weinman, J.; Yiend, J.; Rubin, G.J. A systematic review of factors affecting vaccine uptake in young children. Vaccine 2017, 35, 6059-6069. [CrossRef] [PubMed]

29. Silverman, R.D.; Opel, D.J.; Omer, S.B. Vaccination over Parental Objection-Should Adolescents Be Allowed to Consent to Receiving Vaccines? N. Engl. J. Med. 2019, 381, 104-106. [CrossRef] [PubMed]

Publisher's Note: MDPI stays neutral with regard to jurisdictional claims in published maps and institutional affiliations.

(C) 2020 by the authors. Licensee MDPI, Basel, Switzerland. This article is an open access article distributed under the terms and conditions of the Creative Commons Attribution (CC BY) license (http://creativecommons.org/licenses/by/4.0/). 